\title{
Patient safety and public health concerns: poor dissolution rate of pioglitazone tablets obtained from China, Myanmar and internet sites
}

Mohammad Sofiqur Rahman ${ }^{1 *}$ (D, Naoko Yoshida², Hirohito Tsuboi², Erina Maeda², Andrea Vanessa Velasco lbarra², Theingi Zin³ ${ }^{3}$ Yoshio Akimoto', Tsuyoshi Tanimoto ${ }^{4}$ and Kazuko Kimura ${ }^{1}$

\begin{abstract}
Background: Poor quality medicines have serious implications for public health. The aim of this study was to explore the quality of the antidiabetic pioglitazone, using samples collected in China and Myanmar, and samples purchased online.

Methods: In this cross-sectional study, we examined samples $(n=163)$ collected from hospitals in Shanghai, China in $2012(n=44)$, products purchased via the internet and imported into Japan in $2013(n=59)$, and samples purchased in shops in Yangon, Myanmar in $2015(n=60)$. Collected samples were subjected to visual inspection, authenticity investigation and quality testing (potency, content uniformity and dissolution test) by highperformance liquid chromatography. Samples were rated as compliant or non-compliant based on the relevant pharmacopoeial acceptance criteria.

Results: Visual inspection of all samples revealed compliant products. However, responses from manufacturers during authenticity investigation were poor. Among the $n=44$ samples from China, one was non-compliant in the potency test. Among the $n=59$ samples personally imported into Japan, 38\% of generic samples were found to be non-compliant. In Myanmar, 13.3\% of samples were non-compliant. Non-compliant samples predominantly failed in the dissolution test. All non-compliant samples were generic.

Conclusions: Despite the apparent satisfactory outcome on the samples from China, pioglitazone samples collected in Myanmar and purchased online for personal import into Japan included many substandard products, which failed quality assessment predominantly because of poor dissolution. Internet providers did not comply with Japanese regulations in various respects.
\end{abstract}

Keywords: Medicine, Pharmacoepidemiology, Quality, Substandard, Antidiabetic, Pioglitazone

\footnotetext{
* Correspondence: rahmansofique@staff.kanazawa-u.ac.jp

${ }^{1}$ Medi-Quality Security Institute, Graduate School of Medical Sciences,

Kanazawa University, 920-1192 Kanazawa, Japan

Full list of author information is available at the end of the article
}

(c) The Author(s). 2021 Open Access This article is licensed under a Creative Commons Attribution 4.0 International License, which permits use, sharing, adaptation, distribution and reproduction in any medium or format, as long as you give appropriate credit to the original author(s) and the source, provide a link to the Creative Commons licence, and indicate if changes were made. The images or other third party material in this article are included in the article's Creative Commons licence, unless indicated otherwise in a credit line to the material. If material is not included in the article's Creative Commons licence and your intended use is not permitted by statutory regulation or exceeds the permitted use, you will need to obtain permission directly from the copyright holder. To view a copy of this licence, visit http://creativecommons.org/licenses/by/4.0/ The Creative Commons Public Domain Dedication waiver (http://creativecommons.org/publicdomain/zero/1.0/) applies to the data made available in this article, unless otherwise stated in a credit line to the data. 


\section{Background}

Substandard and Falsified (SF) medicines are a wellestablished threat to public health [1-4]. World Health Organization (WHO) defines 'substandard' medicines which are often termed as 'out of specification' medicines as authorized medical products that fail to meet either their quality standards or specifications, or both. On the other hand, falsified medicines are those that deliberately/fraudulently misrepresent their identity, composition or source [5]. In general, the problem of substandard medicines, as defined by Newton et al. [6, 7], has been overshadowed by the focus on falsified medicines [8-12]. Indeed, the proportion of substandard medicines in circulation is difficult to ascertain because of inadequate reporting. A recent study by the WHO found a failure rate of $10.5 \%$ of tested samples [13], while a review by Caudron et al. stated that the percentage of substandard medicines in several Asian and African countries is in the range of $8-46 \%$ [9]. A similar study in six African countries revealed that $35 \%$ of the collected samples were substandard [12]. Moreover, the problem of substandard medicines is being exacerbated by the rise of online pharmacies [14], which have made drug sub-standardization profitable to unethical manufacturers $[15,16]$. Approximately $60 \%$ of internet users in Japan and the USA use the internet for health-related activities [17]. Thus, there is a clear risk that international trade in pharmaceuticals via sales on the internet will facilitate the entry of poor-quality products into the legitimate supply chain and for the final users.

In this study, we focused on pioglitazone, which is widely used for the treatment of adult type- 2 diabetes mellitus as an adjunct to exercise and diet to improve glycemic control [18]. It is sold in the market as a single product under the brand name Actos or in combination with metformin (Actoplus Met, Actoplus Met XR) and glimepiride (Duetact) $[19,20]$. A few reports on the quality of pioglitazone and other medicines from China or Myanmar have appeared [21-23], and provide useful data for comparison with the findings of this study. Additionally, recent reports on the nitrosamine impurities detected in ranitidine and pioglitazone products suggest the presence of scarce quality pioglitazone products in the market [24, 25].

The aim of this work was to assess the quality of pioglitazone circulating in China and Myanmar, as well as that of pioglitazone sold online for personal import. The information obtained here will be of value to public health officials and pharmaceutical practitioners to determine the extent of the problem, and also to provide a baseline for future studies to evaluate interventions designed to improve the drug supply quality, especially in relation to online imports. It will also help guide further research to better understand the health impact of poorquality medications in these countries.

\section{Methods}

\section{Ethics approval}

Institutional ethical approval was not needed for this study as it is does not involve human subjects, although good ethical practice for such studies has been suggested by Tabernero et al., to maintain the privacy and confidentiality of the surveyors and the surveyed [26]. Regulatory approval was given by the respective countries' Medicine Regulatory Authorities (MRAs), and annual reports have been submitted to them.

\section{Study design and sample collection}

As suggested by the regulatory authorities of the respective countries, pioglitazone was chosen as a target medicine because of the past history of similar medicines to show problems in the dissolution test. The medicine also appears in the essential drug list of Myanmar. The design and analytical methods used in this study followed as far as possible the guidelines of the WHO and those proposed by Newton et al. [27, 28]. Cross-sectional sampling with the mystery shopper approach was used. In each sampling location, the initial sampling plan was to follow a random sampling protocol, though in practice this was not always possible due to the unavailability of medicine, availability of insufficient quantities, incomplete list of shops, or closure of a listed shop at sampling sites [28, 29]. Samples were collected with prescriptions from hospitals and clinics of Huangpu District and Pudong New Area of Shanghai, China, between October and December in 2012. Personally imported samples purchased via internet sites were collected based on the availability of commercial brands in the site during September and December, 2013. Google Japan was used as a search engine to find sites; the search term was ' $ヒ$ ' オグリタゾン AND 個人輸入’ for Japanese language sites and 'Pioglitazone and personal import' for English language sites. In Myanmar, samples were collected without prescription from shops in Yangon during October 2015. The samples were purchased by the mystery shoppers without any preference to specific brands in an attempt to purchase as wide a variety of available commercial brands as possible. Medicines collected from the same shop/site and labeled with the same international non-proprietary name (INN), strength, size, brand name, batch/lot number, and manufacturing and expiry dates were considered as one sample. The maximum number of samples collected from each shop was three.

\section{Sample analysis}

Chemical assessment of the quality of pioglitazone tablets purchased in all the sampling location was carried out at the laboratory of Kanazawa University, Japan. Every sample was placed in an individual ziplock bag together with the recoded data, and securely stored in an 
air-conditioned laboratory $\left(20-25^{\circ} \mathrm{C}\right)$ until analysis. Analysis of all samples was carried out before the stated expiry date. The analysis consisted of observation, authenticity and legality investigation, registration verification, pharmacopoeial analysis (identification, potency, content uniformity and dissolution test) and dissolution profiling.

\section{Visual inspection}

Each sample was given a unique code after the shipment was received. Details of the packaging condition and label information were noted carefully. Observations included the packaging and labeling, and physical appearance of the tablet (size, shape, color, etc.) according to the WHO guideline and the International Pharmaceutical Federation (FIP) checklist for visual inspection of medicines [28-30]. For personal import samples shipped to Japan from internet pharmacies, the websites were checked for compliance with the Pharmaceutical Affairs Law of Japan [31, 32].

\section{Authenticity investigation and legitimacy verification} For the authenticity investigation of the products and legitimacy verification of the manufacturers, a detailed questionnaire was sent to each manufacturer and regulatory authority of the manufacturing country. Sample questionnaire for product authentication and legitimacy verification are presented in Supplemental File S1 and Supplemental File S2. Each questionnaire contained detailed information about the product, including manufacturer, batch number, manufacturing and expiry dates, and dosage and strength of the product, as indicated by WHO and other related studies [17, 28, 29, 33]. The registration status of all products as stated on the product packaging was recorded, and included on a questionnaire sent to the importing country to confirm the registration of the product and manufacturer (sample registration verification form is presented as Supplemental File S3).

\section{Laboratory analysis}

Pioglitazone hydrochloride as a reference standard, benzophenone as an internal standard, methanol, acetonitrile, ammonium acetate, potassium chloride and other chemicals of reagent grade were procured from the Wako Pure Chemical Industries Ltd. Japan. Hydrochloric acid was purchased from Nacalai Tesque Inc. and acetic acid from Alfa Aesar. Analysis of the sample was done by highperformance liquid chromatography (HPLC) according to the modified and validated JP (Japanese Pharmacopoeia) protocol [34, 35], using a Shimadzu Prominence HPLC equipped with a Phenomenex Gemini NX C18 column $(150 \times 4.6 \mathrm{~mm})$ and a UV-photodiode array detector (SPD-20A/20AV Series). The flow rate, injection volume, and detection wavelength were kept unchanged throughout the entire analysis. The dissolution test was performed using $900 \mathrm{~mL}$ of a solution for each of the units with an NTR-VS 6P dissolution apparatus (Toyama Sangyo Co. Ltd., Osaka, Japan). The dissolution medium was prepared by mixing $50 \mathrm{~mL}$ of $0.2 \mathrm{~mol} / \mathrm{L}$ hydrochloric acid and 150 $\mathrm{mL}$ of potassium chloride solution, adding water to make $1000 \mathrm{~mL}$, and adjusting to $\mathrm{pH} 2.0$ with $5 \mathrm{~mol} / \mathrm{L}$ hydrochloric acid. Drug release studies were carried out according to the United States Pharmacopoeia (USP) Type II dissolution apparatus paddle method. The paddle was set to rotate at $50 \mathrm{rpm}$ (revolutions per minute) for $45 \mathrm{~min}$ and the temperature was maintained at $37 \pm 0.50{ }^{\circ} \mathrm{C}$. Standard solutions were prepared by dissolving accurately weighed quantities of pioglitazone hydrochloride (reference standard) and benzophenone (internal standard) in the diluent to obtain concentrations of $0.2 \mathrm{mg} / \mathrm{mL}$ and $0.1 \mathrm{mg} / \mathrm{mL}$, respectively. Serial dilutions were made to $0.025 \mathrm{mg} / \mathrm{ml}$. The concentration of the test solution was kept at $0.1 \mathrm{mg} / \mathrm{ml}$. The relationship between the peak area and concentration of each reference standard was linear within the range of $25-200 \%$ of the active ingredient $\left(r^{2}=\right.$ 0.999-1.000), and the quality test was performed within that range.

\section{Compliance criteria}

Samples were evaluated as meeting the quality specifications if the amount of active pharmaceutical ingredient (API-pioglitazone hydrochloride) in each of the units, as determined by the content uniformity test, lay within the range of $95.0-105.0 \%$ of the label claim. For content uniformity, the acceptance value $(\mathrm{AV} \leqq 15.0)$ was calculated according to USP 34 [36]. In the dissolution test, $\mathrm{Q}=$ $80 \%$ or more was used as the criterion of acceptability as indicated by the pharmacopoeia [34-36].

\section{Statistical analysis}

Descriptive statistical analysis was performed using Microsoft Excel.

\section{Results}

We collected $n=44$ samples from Shanghai, China, $n=$ 60 sample from Yangon, Myanmar and $n=59$ samples personally imported into Japan. Details of the collected samples are presented in the Table 1.

\section{Observational analysis}

No unusual or suspicious features were found for any sample during visual inspection of the samples, except for two samples from one manufacturer, where two different batch numbered strips were found in one box. The physical appearance of the samples was also compliant. However, some serious issues were observed with online sites during sample collection. Among the $n=32$ 
Table 1 Overview of collected samples by sampling site, category and strength

\begin{tabular}{|c|c|c|c|c|c|c|}
\hline \multirow[t]{2}{*}{ Sampling Site } & \multirow[t]{2}{*}{ Year } & \multirow[t]{2}{*}{ Category } & \multicolumn{4}{|c|}{ Strength } \\
\hline & & & $15 \mathrm{mg}$ & $30 \mathrm{mg}$ & $45 \mathrm{mg}$ & $\overline{\text { Total, } \mathrm{n}}$ \\
\hline \multirow[t]{2}{*}{ China (Shanghai) } & 2012 & Originator Brand & 9 & - & - & 44 \\
\hline & & Generic & 35 & - & - & \\
\hline \multirow[t]{2}{*}{ Personal import samples } & 2013 & Originator Brand & 19 & 4 & 5 & 59 \\
\hline & & Generic & 19 & 9 & 3 & \\
\hline \multirow[t]{2}{*}{ Yangon, Myanmar } & 2015 & Originator Brand & 1 & - & - & 60 \\
\hline & & Generic & 59 & - & - & \\
\hline \multicolumn{3}{|c|}{ Total number of samples, $n=$} & \multicolumn{4}{|l|}{163} \\
\hline
\end{tabular}

online sites visited, all were in breach of Japanese regulations in some respect [37]. Site observation results of online pharmacies are summarized in Table 2.

\section{Authenticity, legitimacy investigation, and registration verification}

The response rate to our questionnaire (Supplemental File S1 and Supplemental File S2) was very low, but the manufacturers who replied confirmed their products to be genuine (Table 3). In the case of manufacturing countries, the best response was found for the personal import samples: $71.4 \%$ (5 out of 7) National regulatory authorities (NRAs) confirmed that the manufacturers had approval to manufacture pioglitazone. All the samples collected from Shanghai were found to be registered (Supplemental File S3). Among the $n=60$ collected samples from Myanmar, one sample was found to be unregistered at Food and Drug Administration (FDA), Myanmar.

\section{Results of laboratory analysis}

The results of the identification test are not shown in the table, as all the samples were confirmed to contain pioglitazone. Quantitative analysis by HPLC showed that all samples were within the compliance range (95-105\%), except for one sample from China ( 1 out of $n=44$ samples) among the total of $n=163$ samples from China, Myanmar, and personal import combined (Table 4). The average

Table 2 Observations of internet sites

\begin{tabular}{|c|c|}
\hline Category & $\begin{array}{l}\text { Number of sites } n(\%) ; \\
\text { total, } n=32\end{array}$ \\
\hline Site without any physical address & $6(18.8 \%)$ \\
\hline Site without contact number & $13(40.0 \%)$ \\
\hline Site without purchasing amount restriction & $14(43.8 \%)$ \\
\hline Site without prescription requirement & $32(100.0 \%)$ \\
\hline $\begin{array}{l}\text { Site selling } 45 \mathrm{mg} \text { pioglitazone (not approved } \\
\text { in Japan) }\end{array}$ & $4(12.5 \%)$ \\
\hline $\begin{array}{l}\text { Site delivering a different amount of tablets } \\
\text { from that ordered }\end{array}$ & $4(12.5 \%)$ \\
\hline
\end{tabular}

quantity of API in all the samples was $98.1 \% \pm 2.7$ (mean \pm Standard Deviation-SD) of the label claim. Content uniformity for all samples was within the compliance range (AV value was below or equal to 15). Figure $1 \mathrm{a}, \mathrm{b}$, and $\mathrm{c}$ shows the frequency of the mean API in the quantity test of all samples collected between 2012 and 2015 .

However, In the case of the Myanmar and personal import samples, there was a major problem with dissolution. Figure $1 d$, e, and $f$ shows the frequency of the mean API dissolved in the medium in the dissolution test. In the case of the personal import samples, $n=32$ samples were analyzed for each manufacturer and batch number, and $15.6 \%$ failed to release the required amount of pioglitazone within the specified time. Among the $n=$ 60 Myanmar samples, $13.3 \%$ were non-compliant in the dissolution test. The average percent release of the compliant samples was $95.0 \pm 3.9$ (mean \pm SD). The average percent release of the non-compliant samples is shown in Table 5 and their quantity versus dissolution rate in the dissolution medium are presented in Fig. 2. Time course studies of drug release from the non-compliant samples confirmed that they did not meet the threshold requirement for dissolution time in the dissolution medium (Fig. 3a and b), and most did not disintegrate in the dissolution medium (Supplemental Figure 1 and Supplemental Figure 2).

\section{Discussion}

Our findings revealed serious issues with pioglitazone purchased via the internet and imported into Japan. According to the Pharmaceutical Affairs Law in Japan, selling prescription drugs without a prescription is prohibited, but among the $n=32$ online pharmacy sites visited, none required a prescription to sell pioglitazone (Table 2). In addition, $45 \mathrm{mg}$ pioglitazone is not approved for sale in Japan, but 4 pharmacies were selling this formulation. Also, 14 pharmacies were selling pioglitazone without any restriction on the amount purchased. We found that most of the non-compliant samples were obtained from sites that did not give any physical address (Table 2). 
Table 3 Authenticity investigation and legitimacy verification results of the collected samples

\begin{tabular}{|c|c|c|c|c|c|}
\hline \multirow[t]{2}{*}{ Category } & \multirow{2}{*}{$\begin{array}{l}\text { Replies/total } \\
\text { number }\end{array}$} & \multirow{2}{*}{$\begin{array}{l}\text { Reply on samples/ } \\
\text { number of samples }\end{array}$} & \multicolumn{3}{|c|}{ Authentic, \% } \\
\hline & & & Yes & No & Unknown $^{a}$ \\
\hline \multicolumn{6}{|l|}{ China } \\
\hline Manufacturer & $1 / 9$ & $9 / 35$ & $25.7 \%$ & - & $74.3 \%$ \\
\hline NRA of the manufacturing country & $1 / 2$ & $9 / 35$ & $25.7 \%$ & - & $74.3 \%$ \\
\hline \multicolumn{6}{|l|}{ Personal import samples } \\
\hline Manufacturer & $1 / 11$ & $28 / 59$ & $47.5 \%$ & - & $52.5 \%$ \\
\hline NRA of the manufacturing country & $5 / 7$ & $37 / 59$ & $62.7 \%$ & - & $37.3 \%$ \\
\hline \multicolumn{6}{|l|}{ Myanmar } \\
\hline Manufacturer & $2 / 6$ & $9 / 60$ & $15.0 \% \%$ & - & $85.0 \%$ \\
\hline NRA of the manufacturing country & $1 / 4$ & $1 / 60$ & $1.7 \%$ & - & $98.3 \%$ \\
\hline
\end{tabular}

${ }^{a}$ It was not possible to check if the samples were genuine or the manufacturers were legitimate

On the other hand, the Myanmar samples, which also showed a high failure rate (Tables 4 and 5, Fig. 3), were all of foreign origin, which may suggest that medicines can enter the country through unauthorized channels. The authenticity of the products and legitimacy of the manufacturers remained unclear due to the poor responses to our questionnaire (Supplemental Files S1 and S2) from both manufacturers and medicine regulatory authorities (Table 3), as observed previously [17, 38, 39]. A possible explanation of the low response in the former case might be that manufacturers are already aware that their products are of low quality. However, there is clearly a need to improve legitimacy verification as well $[40,41]$.

In the case of China, only 1 sample out of $=52$ failed to meet the pharmacopoeial requirement for API (Table 4). This may mean that quality of pioglitazone in China is better than has been suggested $[22,42,43]$.

Poor dissolution was the predominant problem among non-compliant samples. Among personally imported samples, up to $8.5 \%$ were substandard (Table 4, Fig. $1 \mathrm{e})$, and $n=3$ released less than $30 \%$ of the required amount (Table 5, Fig. 2). Nevertheless, we could not establish whether these samples were falsified. Among the Myanmar samples, the prevalence was even higher, at 13.3\% (Table 4, Fig. 2). The dissolution test is an important indicator in bioequivalence testing, e.g., to compare generic products with the parent drug. However, many studies have shown that there can be marked differences in dissolution times between originator brand and generic drugs $[12,44-46]$. Time course studies of the noncomplaint samples showed a marked differences in the dissolution behavior compared to the standard sample. Release rate of pioglitazone for most of these non-compliant samples were below the threshold limit even after $180 \mathrm{~min}$ in the dissolution medium (Fig. 3, Supplemental Figure 1 and Supplemental Figure 2). The ineffectiveness of these formulations could easily result in treatment failure.

Table 4 Summary of the results of laboratory analysis

\begin{tabular}{|c|c|c|c|c|c|c|c|}
\hline \multirow[t]{3}{*}{ Sampling Site } & \multirow[t]{3}{*}{ Year } & \multirow[t]{3}{*}{ Test } & \multicolumn{5}{|l|}{ Test (n/\%) } \\
\hline & & & \multicolumn{2}{|c|}{ Originator Brand } & \multicolumn{2}{|l|}{ Generic } & \multirow[t]{2}{*}{ Total samples, $n$} \\
\hline & & & Compliant & Non-compliant & Compliant & Non-compliant & \\
\hline \multirow[t]{3}{*}{ China (Shanghai) } & 2012 & Potency & $9 / 100$ & $0 / 0$ & $34 / 97$ & $1 / 3$ & 44 \\
\hline & & Content Uniformity & $9 / 100$ & 0/0 & $35 / 100$ & 0/0 & \\
\hline & & Dissolution & $9 / 100$ & 0/0 & $35 / 100$ & 0/0 & \\
\hline \multirow[t]{3}{*}{ Personal import samples } & 2013 & Potency & $19 / 100$ & 0/0 & $13 / 100^{\mathrm{a}}$ & $13 / 100^{\mathrm{a}}$ & 59 \\
\hline & & Content Uniformity & $19 / 100$ & 0/0 & $13 / 100^{\mathrm{a}}$ & $13 / 100^{\mathrm{a}}$ & \\
\hline & & Dissolution & $19 / 100$ & 0/0 & $8 / 62^{\mathrm{a}}$ & $5 / 38^{\mathrm{a}}$ & \\
\hline \multirow[t]{3}{*}{ Yangon, Myanmar } & 2015 & Potency & $1 / 100$ & 0/0 & $59 / 98$ & $1 / 2$ & 60 \\
\hline & & Content Uniformity & $1 / 100$ & 0/0 & $59 / 98$ & $1 / 2$ & \\
\hline & & Dissolution & $1 / 100$ & 0/0 & $51 / 86$ & $8 / 14$ & \\
\hline \multicolumn{3}{|c|}{ Total number of samples, $n$} & 163 & & & & \\
\hline
\end{tabular}




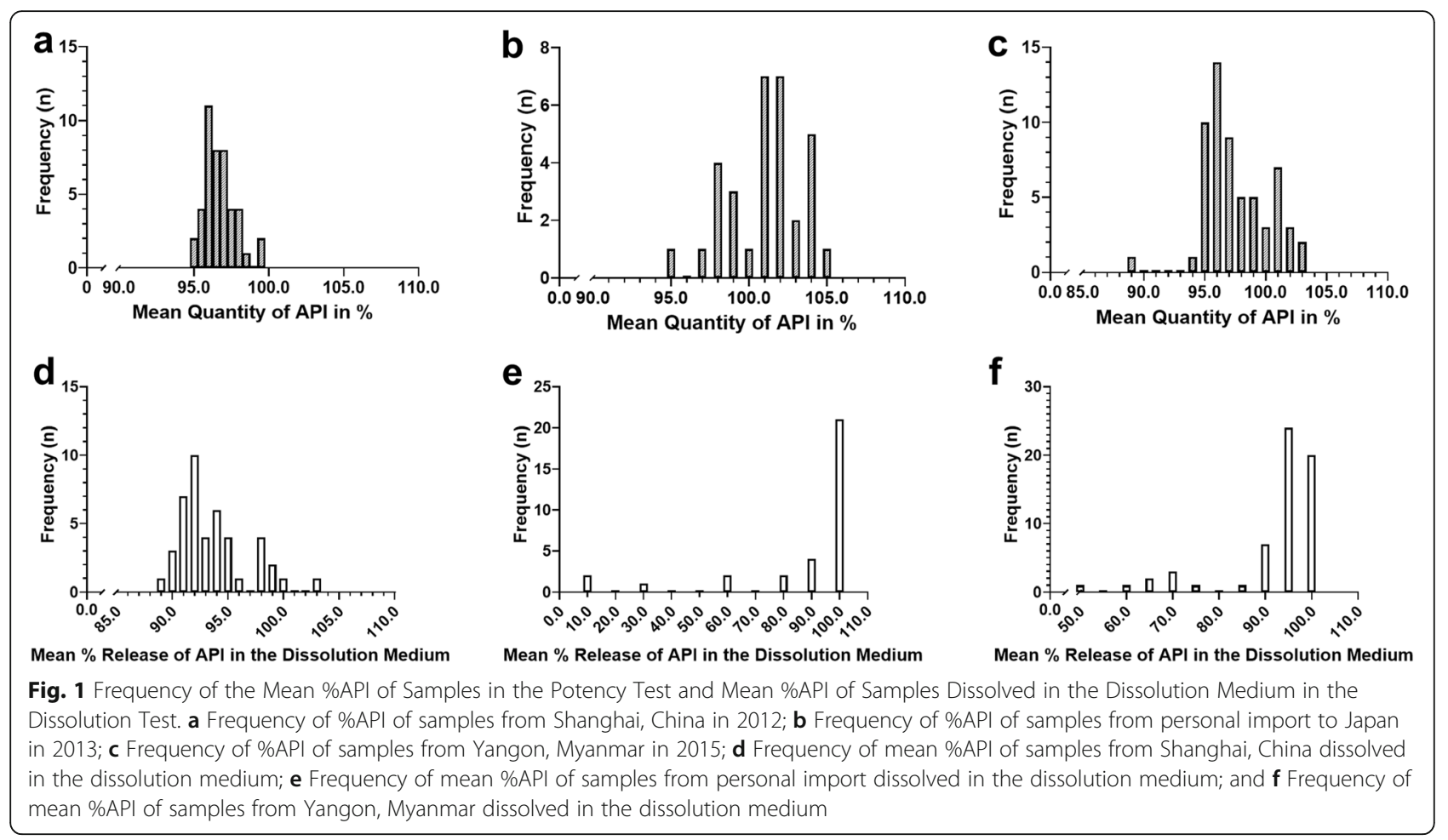

Drug dissolution testing is still being considered to be a minimal requisite in many pharmaceutical quality studies, given that the dissolution testing is one of the key parameter to observe the physicochemical changes in a solid formulation [47].

This study has several limitations. One minor limitation of this study is that the data are relatively old. Medicine regulatory authorities often show reluctance on

Table 5 Average percent release of non-compliant samples in the dissolution test

\begin{tabular}{lll}
\hline Sample source & Sample code & Mean \% release \pm SD \\
\hline Personal import & $23-G E-30-1$ & $12.3 \pm 5.3$ \\
& $25-G E-30-1$ & $11.2 \pm 0.5$ \\
& $31-G E-15-1$ & $26.1 \pm 2.7$ \\
$16-P I O-15-2$ & $61.09 \pm 2.6$ \\
30-GE-30 & $60.3 \pm 2.2$ \\
Yangon, Myanmar & A-032 & $67.0 \pm 7.6$ \\
& A-062 & $68.5 \pm 6.9$ \\
& A-079 & $47.6 \pm 5.8$ \\
& A-086 & $72.6 \pm 5.0$ \\
B-015 & $67.3 \pm 10.0$ \\
B-020 & $69.4 \pm 6.3$ \\
B-107 & $71.2 \pm 11.5$ \\
& PA-013 & $62.0 \pm 5.2$ \\
\hline
\end{tabular}

data sharing and publication. There are also limitations and conditions on data sharing even if they approve and in many cases, it takes longer time than usual to get their final approval. However, the entire process is time consuming and eventually lead to the delayed publication, which is similar to this situation. Additionally, it deals only with a single drug, pioglitazone, collected by a cross-sectional method from specific areas of Myanmar and China, so our results may not reflect the situation in other regions of those countries. Therefore the results may not be directly comparable with other reported findings.

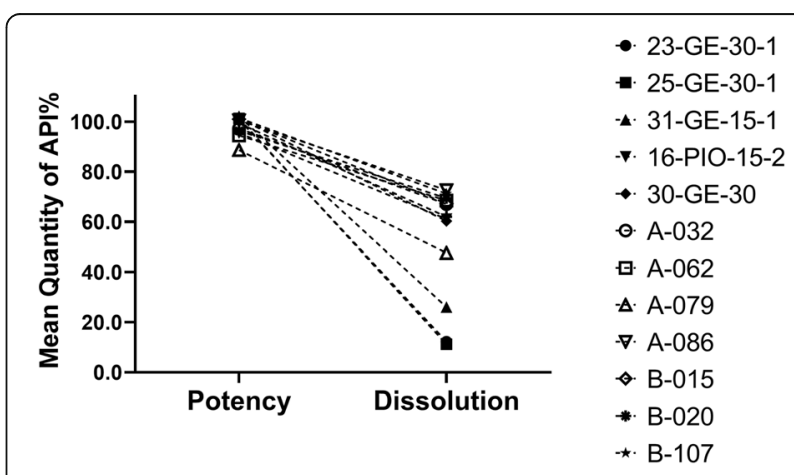

Fig. 2 Mean Quantity of \%API of the Non-Compliant Samples versus their Dissolution Rate in the Dissolution Medium 


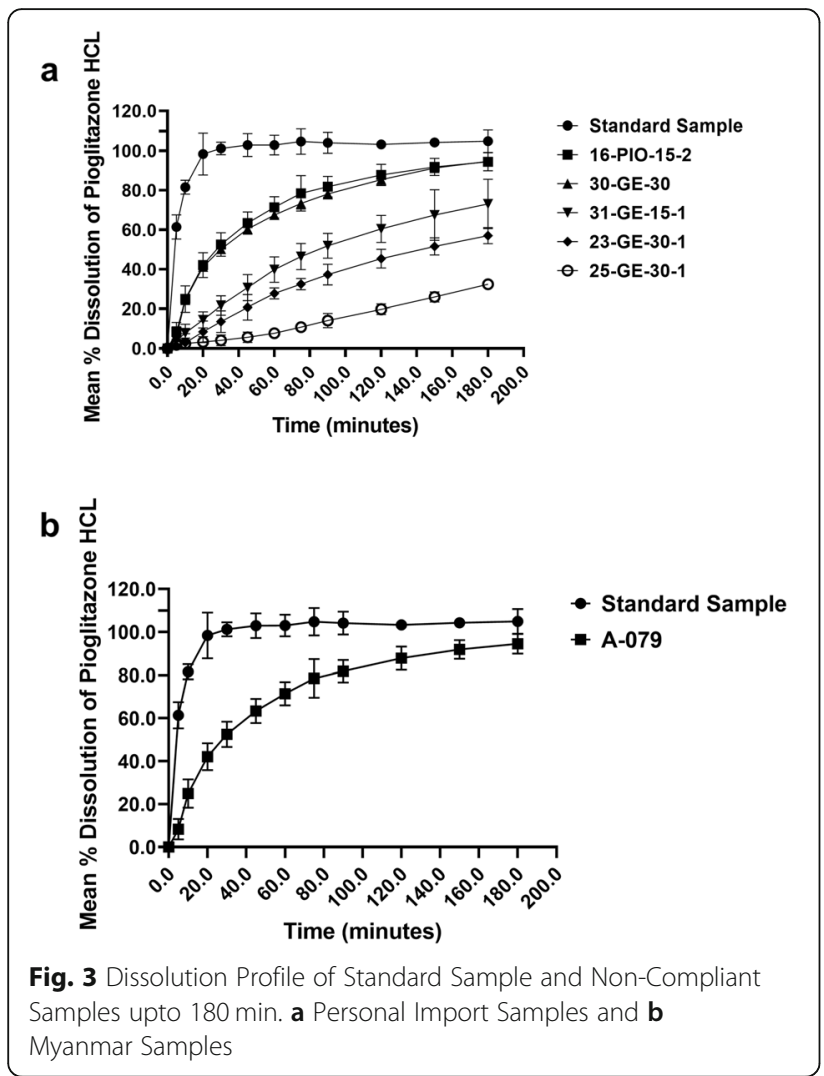

\section{Conclusion}

Many studies still only focus on the content of API which can provide a sense of false security, as the samples are classified as 'good quality' without any information of dissolution/availability. High levels of substandard pioglitazone with poor dissolution properties were identified among samples purchased from online sites and personally imported into Japan, and also among samples collected in Myanmar, whereas only a single sample from China was non-compliant. The internet sites all failed to comply with Japanese law in various respects. Coordinated steps should be taken to ensure best practices including improvement of national and international regulatory oversight to address the situation.

\section{Supplementary Information}

The online version contains supplementary material available at https://doi. org/10.1186/s40360-021-00478-X.

\section{Additional file 1. \\ Additional file 2. \\ Additional file 3.}

Additional file 4: Supplemental Figure 1. Photographs of the tablet of standard and undissolved non-compliant sample from Myanmar in the dissolution vessel. A) Standard sample (Actos) and B) non-compliant sample A-079.
Additional file 5: Supplemental Figure 2. Photographs of the tablet of standard and undissolved non-compliant samples from personal import in the dissolution vessel. A) Standard sample (Actos); B) 16-PIO-15-2; C) 23-GE-30-1; D) 25-GE-30-1; E) 26-GLI-15-1; F) 31-GE-15-1.

\section{Abbreviations}

API: Active pharmaceutical ingredient; AV: Acceptance value; FDA: Food and Drug Administration; FIP : The International Pharmaceutical Federation; HPLC: High-performance liquid chromatography; INN: International nonproprietary name; JP: Japanese Pharmacopoeia; JPMA: Pharmaceutical Manufacturers Association of Japan; MHLW: Ministry of Health, Labour and Welfare; MRA: Medicine Regulatory Authority; NRA: National Regulatory Authority; RPM: Revolutions per minute; SD: Standard Deviation; SF: Substandard and Falsified; USA: United States of America; USP: United States Pharmacopoeia; UV: Ultra-violet; WHO: World Health Organization

\section{Acknowledgements}

The authors are grateful for the support of Japan Pharmaceutical Manufacturers Association (JPMA) and member companies for this project. Without the cooperation and efforts of JPMA, this project would not have been possible, though they had no role in the study design, experiments, the decision to publish, or preparation of the manuscript. We are grateful to Ministry of Health, Labour and Welfare (MHLW), Japan for their help in this project. The authors thank Takeda Pharmaceuticals, Japan for providing an originator brand sample of pioglitazone.

\section{Authors' contributions}

MSR participated in the study design, carried out the experimental study, analysis and drafted the manuscript. EM and AWI conducted the experiments. NY, and HT analyzed the experimental data. NY, TZ, YA, and KK designed and coordinated the study. All authors helped to prepare the draft and approved the final manuscript.

\section{Funding}

Part of this project (China 2012 and Myanmar 2015) was funded by Pharmaceutical Manufacturers Association of Japan (JPMA). Personal Import via Internet in 2013 was funded by Ministry of Health, Labour and Welfare (MHLW), Japan.

\section{Availability of data and materials}

All available data generated or analyzed during this study are included in this article and supplemental files. Raw analysis data for individual sample cannot be provided because of restrictions imposed the respective MRAs.

\section{Ethics approval and consent to participate}

Not applicable (NA)

\section{Consent for publication}

Not applicable (NA)

\section{Competing interests}

The authors have no conflicts of interest to disclose.

\section{Author details}

${ }^{1}$ Medi-Quality Security Institute, Graduate School of Medical Sciences, Kanazawa University, 920-1192 Kanazawa, Japan. ${ }^{2}$ Department of Clinical Pharmacy and Healthcare Sciences, Kanazawa University, 920-1192 Kanazawa, Japan. ${ }^{3}$ Department of Food and Drug Administration (FDA), Ministry of Health and Sports, Naypyidaw, Myanmar. ${ }^{4}$ Pharmaceutical and Medical Device Regulatory Science Society of Japan, 150-0002 Osaka, Japan.

Received: 8 November 2020 Accepted: 17 February 2021 Published online: 02 March 2021

\section{References}

1. Tabernero P, Mayxay M, Culzoni MJ, et al. A repeat random survey of the prevalence of falsified and substandard antimalarials in the Lao PDR: a 
change for the better. Am J Trop Med Hyg. 2015;92(6 Suppl):95-104. https://doi.org/10.4269/ajtmh.15-0057.

2. Khan MH, Hatanaka K, Sovannarith T, et al. Effects of packaging and storage conditions on the quality of amoxicillin-clavulanic acid - an analysis of Cambodian samples. BMC Pharmacol Toxicol. 2013;14:33. https://doi.org/1 0.1186/2050-6511-14-33 Published 2013 Jun 18.

3. Rahman MS, Yoshida N, Tsuboi H, et al. The health consequences of falsified medicines- a study of the published literature. Tropical Med Int Health. 2018;23(12):1294-303. https://doi.org/10.1111/tmi.13161.

4. Zhu S, Yoshida N, Kimura K, Matsushita R, Tsuboi H. Falsified vardenafil tablets available online. J Pharm Biomed Anal. 2020;177:112872. https://doi. org/10.1016/j.jpba.2019.112872.

5. WHO. Definitions of substandard and falsified (SF) medical products. 2017. Available from https://www.who.int/medicines/regulation/ssffc/definitions/ en/\#: :text=Substandard\%3A\%20Also\%20called\%20\%E2\%80\%9Cout\%2 Dof,standards\%20or\%20specifications\%2C\%20or\%20both.\&text=Fa Isified\%3A\%20Medical\%20products\%20that\%20deliberately,their\%2 Oidentity\%2C\%20composition\%20or\%20source. Accessed 12 Oct 2020.

6. Newton PN, Bond KC, Oxford Statement signatories. Global access to quality-assured medical products: the Oxford Statement and call to action [published correction appears in Lancet Glob Health. 2020 Jan;8(1):e38]. Lancet Glob Health. 2019;7(12):e1609-11. https://doi.org/10.1016/S2214-1 09X(19)30426-7.

7. Newton PN, Amin AA, Bird C, et al. The primacy of public health considerations in defining poor quality medicines. PLoS Med. 2011;8(12): e1001139. https://doi.org/10.1371/journal.pmed.1001139.

8. Almuzaini T, Choonara I, Sammons H. Substandard and counterfeit medicines: a systematic review of the literature. BMJ Open. 2013;3(8): e002923. https://doi.org/10.1136/bmjopen-2013-002923.

9. Caudron JM, Ford N, Henkens M, Macé C, Kiddle-Monroe R, Pinel J. Substandard medicines in resource-poor settings: a problem that can no longer be ignored. Tropical Med Int Health. 2008;13(8):1062-72. https://doi. org/10.1111/j.1365-3156.2008.02106.x.

10. Khurelbat D, Dorj G, Bayarsaikhan $E$, et al. Prevalence estimates of substandard drugs in Mongolia using a random sample survey. Springerplus. 2014:3:709. https://doi.org/10.1186/2193-1801-3-709 Published 2014 Dec 2.

11. Katsnelson A. Substandard drugs overshadowed by focus on fakes. Nat Med. 2010;16(4):364. https://doi.org/10.1038/nm0410-364b.

12. Bate $R$, Coticelli $P$, Tren $R$, Attaran A. Antimalarial drug quality in the most severely malarious parts of Africa- a six country study. PLoS One. 2008;3(5): e2132. https://doi.org/10.1371/journal.pone.0002132.

13. WHO. A study on the public health and socioeconomic impact of substandard and falsified medical products. Geneva: World Health Organization; 2017. Available at: http://www.who.int/medicines/regulation/ ssffc/publications/SE_Study_EN.pdf?ua=1. Accessed 22 Apr 2020

14. Rahman MS, Yoshida N, Sugiura S, et al. Quality of omeprazole purchased via the internet and personally imported into Japan: comparison with products sampled in other Asian countries. Tropical Med Int Health. 2018; 23(3):263-9. https://doi.org/10.1111/tmi.13028.

15. Mackey TK, Nayyar G. Digital danger: a review of the global public health, patient safety and cybersecurity threats posed by illicit online pharmacies. Br Med Bull. 2016;118(1):110-26. https://doi.org/10.1093/ $\mathrm{bmb} / \mathrm{ldw016.}$

16. Fittler $A$, Bősze $G$, Botz $L$. Evaluating aspects of online medication safety in long-term follow-up of 136 Internet pharmacies: illegal rogue online pharmacies flourish and are long-lived. J Med Internet Res. 2013;15(9):e199. https://doi.org/10.2196/jmir.2606 Published 2013 Sep 10.

17. Khan MH, Tanimoto T, Nakanishi Y, Yoshida N, Tsuboi H, Kimura K. Public health concerns for anti-obesity medicines imported for personal use through the internet: a cross-sectional study. BMJ Open. 2012;2(3):e000854 https://doi.org/10.1136/bmjopen-2012-000854

18. Shukla R, Kalra S. Pioglitazone: Indian perspective. Indian J Endocrinol Metab. 2011;15(4):294-7. https://doi.org/10.4103/2230-8210.85581.

19. Richter B, Bandeira-Echtler E, Bergerhoff K, Clar C, Ebrahim SH. Pioglitazone for type 2 diabetes mellitus. Cochrane Database Syst Rev. 2006;(4): CD006060. https://doi.org/10.1002/14651858.CD006060.pub2.

20. FDA. Update to ongoing safety review of Actos (pioglitazone) and increased risk of bladder cancer, 2011. Available at: http://www.fda.gov/Drugs/DrugSa fety/ucm259150.htm. Accessed 23 Apr 2020
21. Sakuda M, Yoshida N, Takaoka T, et al. Substandard and falsified medicines in Myanmar. Pharmacy (Basel). 2020;8(1):45. https://doi.org/10.3390/pharma cy8010045.

22. Pan $\mathrm{H}$, Luo H, Chen S, Ba-Thein W. Pharmacopoeial quality of antimicrobial drugs in southern China. Lancet Glob Health. 2016;4(5):e300-2. https://doi. org/10.1016/S2214-109X(16)00049-8.

23. Islam MR, Yoshida N, Kimura $K$, et al. An investigation into the quality of medicines in Yangon, Myanmar. Pharmacy (Basel). 2018;6(3):96. https://doi. org/10.3390/pharmacy6030096 Published 2018 Aug 30.

24. WHO. Information Note Nitrosamine impurities. 2019. Available at: https:// www.who.int/news/item/20-11-2019-information-note-nitrosamineimpurities. Accessed 22 Jan 2021

25. EMA. Lessons learnt from presence of $\mathrm{N}$-nitrosamine impurities. 2020. Available at: https://www.ema.europa.eu/en/documents/report/lessons-lea rnt-presence-n-nitrosamine-impurities-sartan-medicines_en.pdf. Accessed 22 Jan 2021

26. Tabernero P, Parker M, Ravinetto R, Phanouvong S, Yeung S, Kitutu FE, Cheah PY, Mayxay M, Guerin PJ, Newton PN. Ethical challenges in designing and conducting medicine quality surveys. Trop Med Int Health. 2016;21(6): 799-806. https://doi.org/10.1111/tmi.12707 Epub 2016 May 20. PMID: 27102573; PMCID: PMC4913736.

27. Newton PN, Lee SJ, Goodman C, et al. Guidelines for field surveys of the quality of medicines: a proposal. PLoS Med. 2009;6(3):e52. https://doi.org/1 0.1371/journal.pmed.1000052.

28. World Health Organization (WHO). Counterfeit drugs: guidelines for the development for measures to combat counterfeit drugs, 1999. http://apps. who.int/medicinedocs/pdf/h1456e/h1456e.pdf. Accessed 23 Apr 2020.

29. World Health Organization (WHO). Guidelines on the conduct of surveys of the quality of medicines. WHO technical report series, no. 996, 2016, Annex 7. Geneva: Available at: http://apps.who.int/medicinedocs/documents/s224 04en/s22404en.pdf. Accessed 23 Apr 2020.

30. Military and Emergency Pharmacists Section of FIP. Tool for visual inspection of medicines. Available from: https://www.fip.org/files/fip/ counterfeit/Visuallnspection/A\%20tool\%20for\%20visual\%20inspection\%2 0of\%20medicines\%20EN.pdf. Accessed 23 Apr 2020.

31. Ministry of Health, Labour and Welfare (MHLW), Japan. Pharmaceutical Affairs Law, 1960. 1960. Available at: http://law.e-gov.go.jp/htmldata/S35/S3 5HO145.html. Accessed 23 Apr 2020.

32. Ministry of Health, Labour and Welfare (MHLW), Japan. Information for those who are bringing medicines for personal use into Japan. Available at: http:// www.mhlw.go.jp/english/policy/health-medical/pharmaceuticals/01.html. Accessed 23 Apr 2020.

33. Rahman MS, Yoshida N, Tsuboi H, et al. Erroneous formulation of delayedrelease omeprazole capsules: alert for importing countries. BMC Pharmacol Toxicol. 2017;18(1):31. https://doi.org/10.1186/s40360-017-0138-5 Published 2017 May 3.

34. Pioglitazone hydrochloride. In: Supplement II to the Japanese Pharmacopoeia, English version. XV Ed. Ministry of Health, Labour and Welfare (MHLW), Japan. Available at https:/www.pmda.go.jp/files/00015253 6.pdf. Accessed 23 Apr 2020.

35. Pioglitazone hydrochloride. In: Supplement II to the Japanese Pharmacopoeia, English version. XVI Ed. Available at https://www.pmda.go. jp/files/000152770.pdf. Accessed 23 Apr 2020.

36. USP. Pioglitazone. In: United States Pharmocopeia, vol. 2. 34th ed. Rockville: the United States Pharmocopeial Convention; 2010.

37. Ministry of Health, Labour and Welfare (MHLW), Japan. Pharmaceutical Affairs Law (Act No.84 of 2013). Available at: https://www.mhlw.go.jp/english/policy/ health-medical/pharmaceuticals/index.html. Accessed 23 Apr 2020.

38. Rahman MS, Yoshida N, Tsuboi H, et al. A cross-sectional investigation of the quality of selected medicines for noncommunicable diseases in private community drug outlets in Cambodia during 2011-2013. Am J Trop Med Hyg. 2019;101(5):1018-26. https://doi.org/10.4269/ajtmh.19-0247.

39. Khan MH, Okumura J, Sovannarith T, et al. Counterfeit medicines in Cambodia--possible causes. Pharm Res. 2011;28(3):484-9. https://doi.org/1 0.1007/s11095-010-0289-1.

40. Ravinetto R, Pinxten W, Rägo L. Quality of medicines in resource-limited settings: need for ethical guidance. Glob Bioeth. 2018;29(1):81-94. https:// doi.org/10.1080/11287462.2018.1522991.

41. Ravinetto R, Schiavett B. The quality of medicines: an ethical issue? Indian J Med Ethics. 2015;12(4):232-4. https://doi.org/10.20529/JME.2015.061. 
42. Delepierre A, Gayot A, Carpentier A. Update on counterfeit antibiotics worldwide; public health risks. Med Mal Infect. 2012;42(6):247-55. https:// doi.org/10.1016/j.medmal.2012.04.007.

43. Kelesidis T, Falagas ME. Substandard/counterfeit antimicrobial drugs. Clin Microbiol Rev. 2015;28(2):443-64. https://doi.org/10.1128/CMR.00072-14.

44. Johnston A, Holt DW. Substandard drugs: a potential crisis for public health Br J Clin Pharmacol. 2014;78(2):218-43. https://doi.org/10.1111/bcp.12298.

45. Nightingale $\mathrm{CH}$. A survey of the quality of generic clarithromycin products from 18 countries. Clin Drug Investig. 2005;25(2):135-52. https://doi.org/1 0.2165/00044011-200525020-00006.

46. Minzi OM, Moshi MJ, Hipolite D, et al. Evaluation of the quality of amodiaquine and sulphadoxine/pyrimethamine tablets sold by private wholesale pharmacies in Dar Es Salaam Tanzania. J Clin Pharm Ther. 2003; 28(2):117-22. https://doi.org/10.1046/j.1365-2710.2003.00470.x.

47. Okumura J, Taga M, Tey S, Kataoka Y, Nam N, Kimura K. High failure rate of the dissolution tests for 500-mg amoxicillin capsules sold in Cambodia: is it because of the product or the test method? Tropical Med Int Health. 2010 15(11):1340-6. https://doi.org/10.1111/j.1365-3156.2010.02627.x Epub 2010 Sep 24. PMID: 20958889

\section{Publisher's Note}

Springer Nature remains neutral with regard to jurisdictional claims in published maps and institutional affiliations.

Ready to submit your research? Choose BMC and benefit from:

- fast, convenient online submission

- thorough peer review by experienced researchers in your field

- rapid publication on acceptance

- support for research data, including large and complex data types

- gold Open Access which fosters wider collaboration and increased citations

- maximum visibility for your research: over $100 \mathrm{M}$ website views per year

At $\mathrm{BMC}$, research is always in progress.

Learn more biomedcentral.com/submissions 